\section{Scientific journal}

PHYSICAL AND MATHEMATICAL EDUCATION

Has been issued since 2013.

Науковий журнал

ФІЗИКО-МАТЕМАТИЧНА ОСВІТА

Видається з 2013.
ISSN 2413-158X (online)

ISSN 2413-1571 (print)

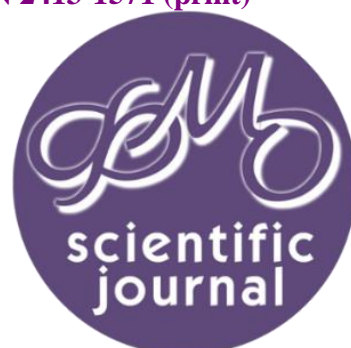

Кудін А.П., Кудіна Т.М., Кархут В.Я. Технологія комп'ютерного тестування при змішаному навчанні в університеті. Фізико-математична освіта. 2021. Випуск 3(29). С. 93-98.

Kudin A., Kudina T., Karhut W. Technology of computer testing in physics for blended learning in university. Physical and Mathematical Education. 2021. Issue 3(29). P. 93-98.

DOI 10.31110/2413-1571-2021-029-3-014

Удк 378.146

А.П. Кудін

Національний педагогічний університет імені М.П. Драгоманова, Україна

kudin@npu.edu.ua

ORCID: 0000-0001-6907-644X

Т.М. Кудіна

Національний педагогічний університет імені М.П. Драгоманова, Україна tamarakudin@gmail.com

ORCID: 0000-0002-8873-8178

В.Я. Кархут

Національний педагогічний університет імені М.П. Драгоманова, Україна v.y.karhut@npu.edu.ua

ORCID: 0000-0002-4632-4479

\title{
ТЕХНОЛОГІЯ КОМП'ЮТЕРНОГО ТЕСТУВАННЯ ПРИ ЗМІШАНОМУ НАВЧАННІ В УНІВЕРСИТЕТІ
}

АНОТАЦІЯ

Формулювання проблеми. Робота присвячена вирішенню проблеми підвищення дискримінативності тестів з фізики шляхом введення нових форм завдань у тесті та процедур проведення комп'ютерного тестування. Гіпотеза дослідження: підвищення ефективності контролю за самостійною роботою студентів при переході українських університетів на змішану форму навчання потребує удосконалення методів і засобів комп'ютерного тестування.

Матеріали і методи. Розробка нових форм завдань у тестах проводилась на основі сучасної теорії дистракторів. Оцінка ефективності завдань нового змісту і форми проводилась в рамках педагогічного експерименту протягом року системи в автоматичному режимі. Аналізувались результати оцінювання навчальних досягнень 91 студента спеціальності 122 «Інженерія програмного забезпечення».

Результати. Проведено аналіз поширених в Україні платформ для організації комп'ютерного тестування (Google Форми, Quіzlet, Proprofs, Kahoot!, ClassMarker, MyTestX, Test 2W, Testing, Plickers, Easy Test Maker i MOODLE). Koнсmamyєmьcя, mo оптимальним рішення при змішаному навчанні - є модуль для тестування у відкритій LMS MOODLE. Haведені приклади вирішення навчальних завдань при вивченні фізики (перевірка системи знань з фізики, формулювання законів, схеми протікання фізичного процесу, алгоритм розв'язку фізичних задач, доведення теорем) за допомоги нових форм тестів. Наведено психолого-педагогічне обгрунтування формулювання дистракторів та введення нових форм тестів. Показана доцільність використання при змішаній формі навчання в університеті двох видів організації комп'ютерного контролю, які мають відмінні процедури проведення: систематична оперативна офлайн-перевірка роботи студента над матеріалом, що виноситься для самостійної роботи, та епізодичний модульний онлайн-зріз знань.

Висновок: використання розроблених технологій комп'ютерного тестування дозволяють значно покращити навчальні досягнення студентів з фізики при змішаному навчанні в університеті.

кЛючОвІ СлОвА: тести, фізика, дистрактори, онлайн, офлайн, дискримінативність.

\section{ВСТУП}

Перехід у 2019 році на змішану форму навчання (використання дистанційних технологій в очному навчанні) закладів вищої освіти України актуалізував процес удосконалення навчальних технологій організації самостійної роботи студентів у віртуальному навчальному середовищі. Але без контролю за самостійною роботою будь-який навчальний процес не можна вважати повноцінним. Єдиною формою контролю за самостійною роботою студентів за таких умов $\epsilon$ віддалене (інтернет) комп'ютерне тестування з автоматизованою перевіркою. Як показала практика (Федосєєва, 2019, Кудін\&Кудіна, 2016), ефективність комп'ютерного тестування як форми проведення об'єктивних зрізів знань зростає, якщо

(C) А.П. Кудін, Т.М. Кудіна, В.Я. Кархут, 2021. 
вони проводяться часто, тести мають великі бази завдань і вони різні за формою. Форми завдань у тестах, як правило, задаються можливостями інформаційних систем тестування.

Аналіз літературних джерел. За даними сайту NAUROK.COM.UA (5, 2021), до найбільш поширених у 2019 році в Україні систем комп'ютерного тестування, орієнтованих на проходження тестування через Вебінтерфейс, належать: Google Форми, Quizlet, Proprofs, Kahoot!, ClassMarker, MyTestX, Test_2W, Testing, Plickers, Easy Test Maker i MOODLE.

Якщо порівняти кількість і якість вирішених навчальних завдань вищої школи у розглянутих платформах і модулі для тестування системи MOODLE (4, 2021), то вони не відрізняються. Окрім того, у LMS MOODLE $€$ можливість розмістити мультимедійних контент, є власні сервіси комунікацій. LMS MOODLE $€$ абсолютно безкоштовною і відкритою. Таким чином, на нашу думку, використання модуля для тестування у LMS MOODLE $є$ оптимальним рішенням для вишів і з погляду дидактики, і з погляду економічної вигоди.

Серед складових організації комп'ютерного тестування (робота над змістом і формою тестів, вибір оболонки для тестування, введення тестів в оболонку, процедура проведення тестування, аналіз результатів тестування) найвагоміший вплив на якість тестування має перша складова. Тобто, робота над змістом і формою питань тестів $\epsilon$ визначальною. Враховуючи проведені за останні роки достатньо глибокі дослідження питань статистичного аналізу результатів тестування, наприклад (Кухар\&Сергієнко, 2010), метою нашого дослідження стало удосконалення таких складових організації комп'ютерного тестування як робота над змістом і формою питань тестів та процедур проведення тестувань.

\section{МЕТОДИ ДОСЛІДЖЕННЯ}

Шаблони форм тестів створювались сервісами LMS MOODLE. Мережеве тестування проводилось протягом року в автоматичному режимі: отримувались результати оцінювання навчальних досягнень 91 студента спеціальності 122 «Інженерія програмного забезпечення». Для побудови варіаційних кривих використовувались дані з модуля для тестування системи MOODLE. При аналізі індивідуальних результатів зрізів знань додатково використовувалося анкетування студентів.

\section{РЕЗУЛЬТАТИ ДОСЛІДЖЕННЯ ТА ОБГОВОРЕННЯ}

При складанні тестів певних форм робота зводиться до формулювання дистракторів. Деякі методисти (Кухар\&Сергієнко, 2010) вважають, що дистрактори - це неточні відповіді, які мають допомогти учневі оволодіти навчальним матеріалом, а не вносити хаос в осмислення ним такого матеріалу. Якщо спиратись на точність перекладу, то англійське слово «distractor» утворене від дієслова «distract» (відволікати). На нашу думку, дистрактори - це точні відповіді, але вони не відповідають тому, про що йдеться у запитанні.

Тепер перейдемо до апробованих в дослідженні форм тестів. Будуть запропоновані різні форми тестових завдань залежно від того, що перевірялося у фізиці: закон, означення, процес, явище, алгоритм, доведення теореми, формули.

Перша форма: на перевірку визначення фрізичного закону або означення (Таблиця 1).

Таблиця 1

Під якими числами у визначенні, що передає зміст аксіоми інерції , вжиті неправильні слова:

\begin{tabular}{|l|l|}
\hline 1 & Абсолютно тверде тіло \\
\hline 2 & буде перебувати \\
\hline 3 & в спокої \\
\hline 4 & при дії двох сил \\
\hline 5 & тоді, коли вони \\
\hline 6 & однакові за величиною \\
\hline $7^{*}$ & однакові за напрямком \\
\hline 8 & мають одну точку прикладання \\
\hline
\end{tabular}

Щоб створити таку форму тесту, формулювання фізичного закону чи означення, яке перевіряється, розбивається на логічно пов'язані між собою слова. Їм присвоюються порядкові номери. Але серед них (у Таблиці 1 - це фраза під номером 7) вносяться слова, які не належать цьому формулюванню. Але відносяться до іншого відомого означення чи закону. Тобто, це дистрактор, який «відволікає». Таким чином створюється психологічна ситуація, коли дистрактори не вносять хаос в осмислення навчального матеріалу.

Позначення окремих дистракторів числами позв'язане з тим, що це найбільш надійна форма передачі відповіді, де не може бути технічної помилки в результаті набору. На відміну, наприклад, від форми відповіді як «введення слова з клавіатури».

Вказаний підхід може бути використаний і для перевірки схеми фізичного процесу, явища або алгоритму розв'язання певної фізичної задачі. У прикладі тестового питання (Таблиця 2) перевіряється точне розуміння послідовності кроків в алгоритмі розв'язання однієї задачі в статиці:

Табличя 2

Що можна не робити при розв'язуванні задач в статиці з використанням умови рівноваги:

\begin{tabular}{|l|l|}
\hline 1 & зобразити всі сили на рисунку \\
\hline $2 *$ & знайти і показати рівнодійну силу \\
\hline 3 & ввести тіло відліку \\
\hline 4 & ізя'язану з ним систему координат \\
\hline 5 & осі на рисунку розмістити у зручному вигляді \\
\hline 6 & обрахувати проекції усіх сил на осі координат \\
\hline 7 & $\begin{array}{l}\text { записати рівняння, у ліву частину яких входять суми } \\
\text { проекцій усіх сил на відповідну вісь }\end{array}$ \\
\hline 8 & розв'язати рівняння \\
\hline
\end{tabular}


Друга форма: перевірка доведення теорем або законів.

Більшість практиків вважає, що автоматизована комп'ютерна перевірка доведення теореми чи виведення формули практично неможлива, бо важко передбачити усі можливі варіанти слів (або їх послідовність) у тексті доведення, які може вжити студент. Наприклад, фрази «Візьмемо силу...», «Нехай маємо силу...», «Якщо ми маємо силу...» мають однаковий зміст, але при автоматизованій перевірці комп'ютером може бути оцінено не однаково.

Нижче наведено приклад тестового завдання (рис.1), яке перевіряє правильність доведення однієї теореми механіки: теорема про миттєвий центр швидкостей при плоскопаралельному русі.

Приклад.

Прочитайте уважно доведення теореми. Чи все там викладено правильно. Виберіть варіант правки.

Нехай маємо деяке тіло, що рухається плоско паралельно, і точка А - полюс, що має швидкість $\overrightarrow{v_{A}}$, як показано на рисунку. Проведемо через т.F лінію перпендикулярну до вектору швидкості $\bigcup_{A}$. За означення плоско-паралельного

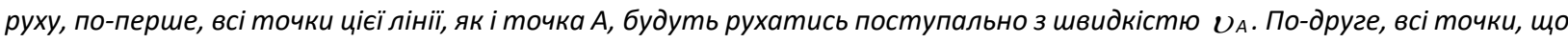
знаходяться на цій лінії, будуть обертатися навколо т. А.

Покажемо вектори лінійних швидкостей точок обертального руху. Згідно формули Ейлера - чим далі точка від осі обертання, тим лінійна швидкість буде більшою. Знайдемо результуючі швидкості точок $M_{1}, M_{2}, M^{\prime} . M_{\text {мона }}$ передбачити, що існує така точка М', в якій лінійна швидкість обертального руху і швидкість поступального руху будуть однакові. Тоді результуюча швидкість точки $M^{\prime}$ дорівнюватиме нулю. Отже, при плоско паралельному русі тіла існує точка тіла, миттєва швидкість якої дорівнює нулю.

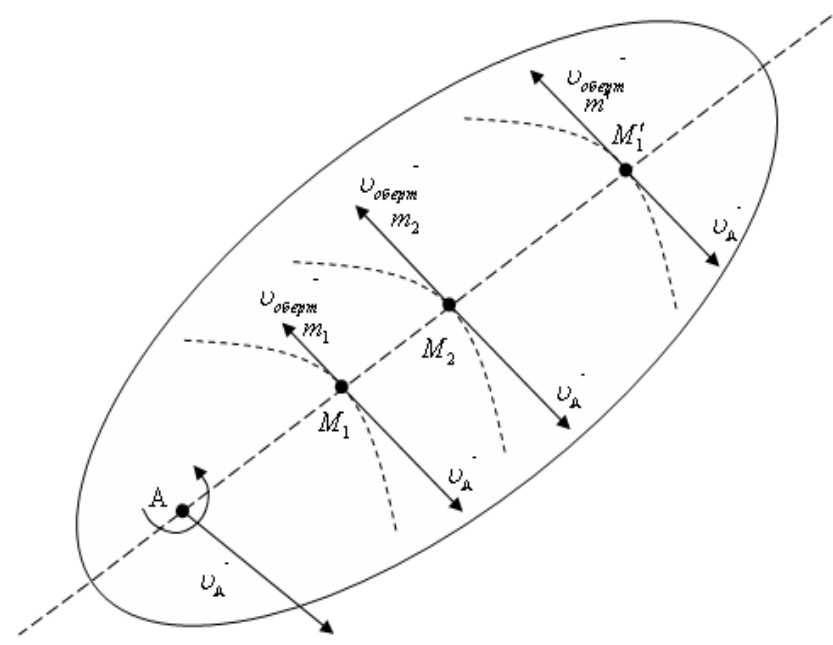

Рис. 1. Доведення теореми про існування миттєвого центру швидкостей

Варіанти правок.

1.Виправлення виділено - «Нехай маємо абсолютно тверде тіло, що рухається плоско паралельно...»

2.Виправлення виділено - «За формулою Ейлера для швидкостей точок при плоско-паралельному русі, по-перше,

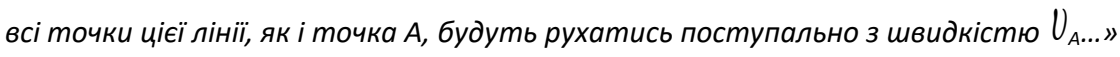

3.Виправлення виділено - «Згідно формули Ейлера - чим далі точка від осі обертання, тим кутова швидкість буде більшою».

4.Виправлення виділено - «Можна передбачити, що існує декілька точок М', в яких лінійна швидкість обертального руху...».

5.Виправлення виділено - «Отже, при плоско паралельному русі тіла існує точка тіла, відносна швидкість якої дорівнює нулю».

6.Все правильно.

Усі правки - це дистрактори, які відповідаю вимогам, що зазначені вище. У тексті, який бачить студент, виділених місць знаходження правок немає. Тобто студентові потрібно уважно (!) перечитати не один раз текст, щоб відшукати місце правки, яка пропонується; прийняти рішення про заміну чи не заміну правки. Це теж важливий навчальний момент: багаторазове повторення (перечитування) фрагментів того, що раніше було прочитане, може викликати відновлення в пам'яті всього тексту. Ця особливість пам'яті у психологів називається фрагментарністю (Зефиров \& 3иятдинова, 2015).

Але в наведеному прикладі використовується ще один прийом психологічного впливу на студента: це наявність дистрактора під №6. Студент після перегляду усіх смислових дистракторів попадає у таку ситуацію, коли натрапляє на найпростіше рішення - дистрактор «все правильно». Практика показала, що більшість студентів чомусь не обирають цей дистрактор. Анкетування студентів показало, що вони «не вірить в те, що викладач придумував п'ять неправильних дистракторів».

Третя форма: перевірка формул.

Переважна більшість формул у фізиці має знак рівності.

Практика показала, що складнішими на вигляд $€$ питання на перевірку формул у випадку, коли у питанні відсутня одна з частин цього рівняння (Таблиця 3). 
Встановити відповідність, що виражають формули:

\begin{tabular}{|l|l|l|l|}
\hline $\mathbf{1}$ & $\sqrt{\frac{k}{m}}$ & $\mathrm{~A}$ & Проекція «поновлюючої» сили \\
\hline $\mathbf{2}$ & $\left(k_{0} t+\alpha\right)$ & Б & Період \\
\hline $\mathbf{3}$ & $-k x$ & $\mathrm{~B}$ & Фаза \\
\hline $\mathbf{4}$ & $\frac{2 \pi}{k_{0}}$ & Г & Частота \\
\hline $\mathbf{5}$ & $\frac{x}{\sin (k t+\varphi)}$ & Д & Амплітуда \\
\hline
\end{tabular}

\section{Процедури проведення комп'ютерного тестування.}

у Навчальній програмі дисципліни «Фізика (вибрані питання). Фізичні основи роботи елементів комп'ютера», $\epsilon$ теми, які виносяться на самостійне опрацювання, і студентові необхідно вивчити цей матеріал до наступного аудиторного заняття. Отже, розгляд цих питань не можна відкласти на кінець навчального року. Крім того, у студента має бути впевненість, що він зрозумів ці питання правильно і готовий перейти до вивчення нової теми на наступному аудиторному занятті. А після вивчення окремих модулів (розділів) студент має достатні знання, щоб пройти атестацію навчальних досягнень за 100-бальною системою. Практика показала доцільність використання при змішаній формі навчання в університеті таких видів комп'ютерного контролю, які мають відмінну процедуру проведення: систематична оперативна офлайн-перевірка роботи студента над матеріалом, що виноситься для самостійної роботи та епізодичний модульний онлайн-зріз знань.

\section{1.Оперативна офлайн-перевірка самостійної роботи студента.}

Місце проведення. Віддалене тестування організовано в модулі для тестування в інтернет-доступному курсі «Фізика» у MOODLE для авторизованих студентів.

Процедура тестування. Відповідно до зазначеної вище навчальної мети умови реалізації даного виду віддаленого комп'ютерного тестування мають такий вигляд: частота проведення тестування визначається кількістю вивчених тем (після кожної теми); форма нескладна (наприклад, «одна правильна відповідь і 3-4 «неправильні»); спроба одна; термін здачі - до наступного заняття протягом тижня; тривалість тестування визначається експериментально (До часу прочитання тексту запитання і усіх його дистракторів додається 15 секунд. Такі «жорсткі» часові рамки цього виду тестування обумовлені тим, що, як показують результати практичних робіт 3 комп'ютерної текстології (Федосєєва\&Нечепоренко, 2019), обмеження часу на обдумування, як правило, виключає можливість користуватися додатковими джерелами під час тестування.); тест на невелику кількість балів (2-3 бали при тому, що модульний 30 балів! Це зроблено з метою, щоб не було бажання у студента звернутись до іншої особи з проханням виконати за нього); питання в тесті обирає генератор випадкових чисел - стандартна функція формування варіантів білетів при комп'ютерному тестуванні; оцінка за тест стає відомою студентові одразу після його здачі, але повний протокол відповіді оприлюднюється після закінчення термінів здачі всіх робіт студентів, що встановлюється в системі MOODLE викладачем. Це зроблено для неотримання інформації про правильні відповіді студентами, які будуть здавати тест останніми.

\section{2.Онлайн модульний зріз.}

Місцем проведення цього виду тестування є модуль для тестування в інтернет-доступному курсі «Фізика» у MOODLE для авторизованих студентів, але з іншими налаштуваннями і проводиться в мережевому класі під наглядом через Web-камери.

Головним завданням другого виду комп'ютерного тестування $€$ об'єктивний зріз знань великого обсягу навчального матеріалу. Тому умови процедури тестування більш «жорсткі»: ідентифікація осіб у мережевому класі перед початком тестування; завдання розрізняються за рівнем складності; вибір відповіді - з клавіатури; відсутні часові обмеження на обдумування питання; 1 раз на місяць; проводиться у заздалегідь визначений час (до 1 години); присутність викладача обов'язкова; основний внесок у рейтинг студента (наприклад, три тестування по 30 балів).

Оцінка есрективності запропонованих форм тестів.

Нами був проведений аналіз тесту в цілому на його дискримінативність. Це - найголовніший критерій ефективності будь-якого тесту, особливо педагогічного (Кухар\&Сергієнко, 2010). Дискримінативність - це здатність тесту в цілому диференціювати обстежуваних студентів відносно максимального і мінімального результатів тесту. У нашому випадку перевірити, наскільки ефективно запропоновані форми тестів виконали навчальне завдання з перевірки рівня залишкових знань.

Дискримінативність точно вимірюється показником дельта Фергюсона, але може бути оцінена із характеру розподілу кількості обстежуваних по інтервалах балів від мінімального до максимального значення. У даному дослідженні дискримінативність тесту перевірялась з допомогою варіаційних кривих (в 10 послідовних інтервалах балів, на які розбивається шкала від 0 до 100 балів), побудованих на основі результатів зрізів знань, проведених протягом семестру (рис. 2). Дані отримували з модуля для тестування системи MOODLE в автоматизованому режимі.

3 погляду загальної теорії тестів (Федосєєва\&Нечепоренко, 2019) яскраво виражений максимум варіаційної кривої в певній області балів свідчить про низьку дискримінативність тестів. Наприклад, якщо це область малих балів, тест в цілому важкий для студентів конкретної групи і потребує докорінної переробки. Як видно із рис. 2, дискримінативність даного тесту є високою: крива має широкий максимум, який охоплює значну частину інтервалів позитивних балів. Це означає, що даний тест в цілому виконав своє навчальне завдання - «розподілити» студентів на осіб з низьким, середнім і високим рівнем знань. 


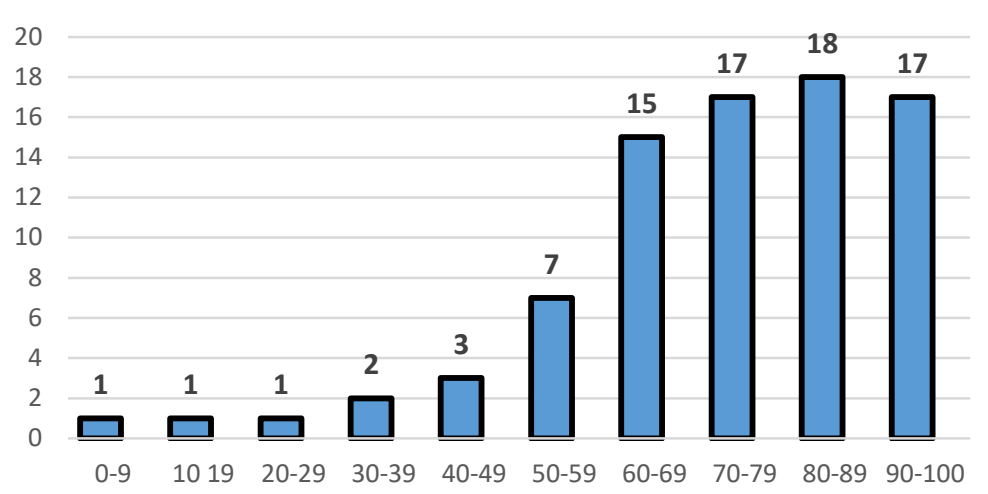

Рис.2. Розподіл кількості студентів за балами (0-100) при використанні запропонованих форм тестів і процедури комп'ютерного тестування

\section{вИСновки}

Запропоновані форми питань комп'ютерних тестів з фізики, які базуються на теорії дистракторів, розв'язують низку важливих навчальних завдань вищої школи (систематизацію знань з фізики, перевірку формулювань законів, схем протікання фізичного процесу, знання алгоритму розв'язку фізичних задач і доведення теорем). Визначено, що оптимальними у закладах вищої освіти при змішаній формі навчання $€$ два види комп'ютерного тестування: систематична офлайн-перевірка знань матеріалу, що виноситься на самостійне опрацювання і модульний онлайн-зріз знань у мережевому класі. Результати педагогічного експерименту показали, що удосконалена форма тестів і запропонована процедура проведення комп'ютерного тестування дозволяють досягнути високої дискримінативності тестів. Подальшого дослідження потребують адитивні технології тестування з елементами штучного інтелекту, виготовлені у формі мобільних застосунків для проведення оперативного онлайн-опитування студентів.

\section{Список використаних джерел}

1. Зефиров Т.Л., Зиятдинова Н.И., Купцова А.М. Физиологические основы памяти. Развитие памяти у детей и подростков. Казань, КФУ, 2015. 40 с.

2. Кудін А.П, Кудіна Т.М., Кархут В.Я. Програмне забезпечення та інтерактивні інформаційні системи. Збірник наукових праць Кам'янець- Подільського національного університету імені Івана Огієнка. Серія педагогічна/ ред.: П.С. Атаманчук (голова, наук. ред) та ін./ [Кам'янець-Подільський національний університет імені Івана Oriєнка, 2016. Випуск 22: Дидактичні механізми дієвого формування компетентністних якостей майбутніх фахівців фізики і техніки. С. 194-197.

3. Кухар Л.О., Сергієнко В.П. Конструювання тестів. Курс лекцій: навч. посіб. Луцьк, 2010. 182 с.

4. Сайт LMS MOODLE URL: https://moodle.com/lms/ (дата звернення 08.05.2021).

5. Сайт «Онлайн-тести «На Урок». URL: https://naurok.com.ua/test (дата звернення 08.05.2021).

6. Федосєєва О. В., Нечепоренко А.Г. Ефективність комп'ютерного тестування у навчальному процесі в медичних ВНЗ. Науковий огляд. 2019. № 5.С. 1-10.

\section{References}

1. Zefirov T.L., Zijatdinova N.I., Kupcova A.M. (2015) Fiziologicheskie osnovy pamjati. Razvitie pamjati u detej i podrostkov. Kazan', KFU, [in Russian].

2. Kudin A.P, Kudina T.M., Karkhut V.la. (2016) Prohramne zabezpechennia ta interaktyvni informatsiini systemy Zbirnyk naukovykh prats Kamianets-Podilskoho natsionalnoho universytetu imeni Ivana Ohiienka. Seriia pedahohichna./ red.: P.S.Atamanchuk (holova, nauk. red) ta in./ [ Kamianets-Podilskyi natsionalnyi universytet imeni Ivana Ohiienka, - Vypusk 22: Dydaktychni mekhanizmy diievoho formuvannia kompetentnistnykh yakostei maibutnikh fakhivtsiv fizyky i tekhniky. S. 194197. [in Ukrainian]

3. Kukhar L.O., Serhiienko V.P. (2010) Konstruiuvannia testiv. Kurs lektsii: navch. posib. Lutsk, [in Ukrainian]

4. Sait LMS MOODLE Retrieved from https://moodle.com/lms/ (data zvernennia 08.05.2021). [in Ukrainian].

5. Sait «Onlain-testy «Na Urok». Retrieved from https://naurok.com.ua/test (data zvernennia 08.05.2021). [in Ukrainian]

6. Fedosieieva O. V., Necheporenko A.H. (2019) Efektyvnist kompiuternoho testuvannia u navchalnomu protsesi v medychnykh VNZ. Naukovyi ohliad. № 5.S. 1-10. [in Ukrainian]

\section{TECHNOLOGY OF COMPUTER TESTING IN PHYSICS FOR BLENDED LEARNING IN UNIVERSITY}

\section{A.P. Kudin, T.M. Kudina, W.Y. Karhut}

Drahomanov National Pedagogical University, Ukraine

Abstract.

Formulation of the problem. The article is devoted to solving the problem of increasing discriminar parameter of tests in physics by introducing new forms of tasks in the test and procedures for computer testing. Research hypothesis: the improvement of methods and tools of computer testing is necessary to increase the effectiveness of control over the independent work of students in the transition of Ukrainian universities to a blended form of education. 
Materials and methods. The development of new forms of tasks in the tests was carried out on the basic of modern distractor theory. Evaluation of new tasks effectiveness was carried out as part of a pedagogical experiment during the year in automatic mode. The assessment results of academic achievements of 91 students specialty 122 "Software Engineering" were analyzed.

Results. The author analyzes the most common in Ukraine platforms for the organization of computer testing system (Google Forms, Quizlet, Proprofs, Kahoot, ClassMarker, MyTestX, Test_2W, Testing, Plickers, Easy Test Maker and MOODLE). For his opinion, the optimal module for testing is learning management system MOODLE It can solve the existing problems in blended learning. The pre-work on the content and form of test requests is determining for organization of testing. The author gives examples of solving educational problems in physics studying (checking knowledge, formulation of laws definition, schemes for the physical process, an algorithm for the solution of physical problems, the introduction of the theorem) using new forms of tests based on modern research theory. There are two types of computer control, which have different procedures. The first one is the systematic operational offline verification of the student's work; the second one is episodic module online checking.

Conclusion: the developed computer testing technologies can significantly improve the students educational achievements in Physics educating for a blended form at the university.

Key words: tests, physics, distractors, online, offline, discriminar. 